A fine needle on a syringe was introduced through the cyst wall, and air under pressure pushed the syringe barrel outwards. At this point the surgeon and the anaesthetist realised that this pharyngocele had resulted from the inflated cuff of the laryngeal mask used. It was more prominent through the head having been turned to the opposite side. The "diagnostic" puncture of the cuff resulted in a slow deflation, which eventually necessitated the replacement of the mask owing to the development of laryngeal spasm. The surgeon was relieved of the need for further investigation of the swelling.

M HARDINGHAM

M M HILLS

Gloucestershire Royal Hospital

Gloucester GL1 3NN

1 O'Meara ME, Jones JG. The laryngeal mask. BMf 1993;306: 224-5. (23 January.)

EDITOR, - I am much less enthusiastic about the wholesale introduction of the laryngeal mask in this country than Moira E O'Meara and J Gareth Jones. ${ }^{1}$ An anaesthetist's ability to maintain airway patency by using a conventional facemask is not a skill easily acquired, nor is it made redundant by this new piece of equipment. There are circumstances-and I include cases of upper airway obstruction, epiglottitis being an obvious example -when such expertise is crucial to successful management.

There is a real danger that trainees who in their early years depend too much on the laryngeal mask will find themselves insufficiently experienced in this vital aptitude. It behoves those responsible for training junior anaesthetists to postpone any introduction to this novel device until the good old standby of bag and mask anaesthesia has been mastered.

Edith Cavell Hospital,

Peterborough PE3 6GZ

1 O'Meara ME, Jones JG. The laryngeal mask. BMF 1993;306: 224-5. (23 January.)

\section{Gestational diabetes mellitus}

EDITOR,-I am concerned about some of the analyses in Professor Jarrett's review of gestational diabetes.' A lack of consensus about terminology and definitions hampers progress, but does not imply that a problem is non-existent. He omits the work of the Diabetes Pregnancy Study Group of the European Association for the Study of Diabetes. This group has carried out a large multicentre study on glucose tolerance in normal pregnancy. ${ }^{2}$ It showed that more than $10 \%$ of normal pregnant women had two hour glucose concentrations after a $75 \mathrm{~g}$ glucose tolerance test of more than $8 \mathrm{mmol} / \mathrm{l}$ and were thus labelled as having impaired glucose tolerance. Pregnancy is clearly having an effect on glucose tolerance, a fact Jarrett dismisses. Indeed, in one longitudinal study in normal women, significant metabolic differences could be found over only one month in the third trimester. ${ }^{3}$ In view of the changes in glucose tolerance in pregnancy Lind $^{2}$ has recommended that for a $75 \mathrm{~g}$ glucose tolerance test the two hour cut off should be $9 \mathrm{mmol} / \mathrm{l}$ and for the one hour test, $10.5 \mathrm{mmol} / \mathrm{l}$. He further recommends the use of the term gestational impaired glucose tolerance for those women whose two hour value lies between 9 and 11 $\mathrm{mmol} / \mathrm{l}$, reserving the term gestational diabetes for those women who have a result indicating diabetes on a glucose tolerance test in pregnancy.

Jarrett dismisses excessive birth weight as being secondary to maternal obesity rather than glucose tolerance abnormalities. Although obesity seems to be the major factor, he fails to cite studies showing that glucose tolerance remains a significant factor even after allowance for maternal obesity. 4

Jarrett ignores studies that have investigated perinatal morbidity in association with abnormal results on a glucose tolerance test. In a study of over 200 women with abnormal results, each woman was compared with a control matched for obesity, age, ethnicity, and parity and who had screened negative for glucose intolerance. ${ }^{6}$ Results showed that stays on the neonatal care unit of more than 48 hours (brief admissions because of the labe diabetes were excluded) were significantly more common in those with abnormal results. Furthermore, with worsening glucose abnormalities the neonatal morbidity in terms of hypoglycaemia and polycythaemia was increased. Maternal obesity was not a significant factor.

Jarrett finishes by recommending that screening for abnormalities of glucose tolerance in pregnancy be discontinued. Even if one ignores any effects on the fetus and neonate, what about the mother? The longest follow up reported is by O'Sullivan. Reviewing women at between 22-28 years after the index pregnancy (when they had had abnormal glucose tolerance, but reverted to normal tolerance afterwards), he found a $50 \%$ prevalence of diabetes and $25 \%$ of abnormal glucose tolerance, whereas the controls had rates of $7 \%$ and $3 \%$. The stress of pregnancy on the maternal pancreas provides a most powerful predictor of the subsequent development of impaired glucose tolerance and diabetes. Thus women with a high probability of developing such problems can be separated out for preventive therapy research programmes, in an effort to decrease the morbidity and mortality these women subsequently suffer.

St Mary's Hospital for Women and Children,

MICHAEL MARESH Manchester M13 0JH

1 Jarrett RJ. Gestational diabetes mellitus: a non-entity? $B M \mathcal{J}$ 1993;306:37-8. (2 January.)

2 Lind TA. Prospective multicentre study to determine the influence of pregnancy upon the $75 \mathrm{~g}$ oral glucose tolerance test (OGTT). In: Sutherland HW, Stowers JM, Pearson DWM, eds. Carbohydrate metabolism in pregnancy and the newbom. Heidelberg: Springer-Verlag, 1989:209-26.

3 Maresh M, Gillmer MDG, Beard RW, Alderson C, Bloxham B, Elkeles RS. The effect of diet and insulin on metabolic profiles of women with gestational diabetes mellitus. Diabetes 1985.34 of women with

4 O'Sullivan JB, Gellis SS, Dandrow RV, Tenney BO. The potential diabetic and her treatment in pregnancy. Obstet Gynecol 1966;27:683-9.

5 Freinkel N, Metzger BE, Phelps RL, Dooley SL, Ogata ES, Radvany RM, Belton A. Gestational diabetes mellitus. Radvany RM, Belton A.
Diabetes 1985;34(suppl 2):1-7.

6 Maresh M, Beard RW, Bray CS, Elkeles RS, Wadsworth J. Factors predisposing to and outcome of gestational diabetes. Obstet Gynecol 1989;74:342-6.

7 O'Sullivan JB. Subsequent morbidity among gestational diabetic women. In: Sutherland HW, Stowers JM, eds. Carbohydrate metabolism in pregnancy and the newborn. Edinburgh: Churchil Livingstone, 1984:174-80.

EDITOR, - R J Jarrett has put forward the epidemiologist's view of gestational diabetes, pointing out the lack of a clear definition, the lack of consensus on treatment, and evidence suggesting that maternal glycaemia is not important in determining fetal size.' All of these points are well taken. Nevertheless, most clinicians would not view a mother with impaired glucose tolerance in pregnancy with the same sangfroid as epidemiologists, who view the data from afar. Why the discrepant views?

We recently retrospectively reviewed the data on mothers who had mild degrees of impaired glucose tolerance at Central Middlesex Hospital. It is policy to screen all mothers with risk factors for gestational diabetes (family history of diabetes, previous gestational diabetes, poor obstetric history, clinical polyhydramnios, maternal obesity, or previous macrosomic infant $(>4000 \mathrm{~g})$ with a $75 \mathrm{~g}$ oral glucose tolerance test at 30 weeks' gestation. In 260 pregnancies $(3.7 \%$ of the total) the two hour glucose value on testing was $>6.9 \mathrm{mmol} / \mathrm{l}$, and clinical details of the mother and baby were obtained from the case notes in these cases. Of relevance to the present argument were the correlations with the babies' birth size.

On regression analysis with birth weight as the dependent variable and maternal body mass curve, maternal weight gain during pregnancy, maternal age, and area under the glucose curve as independent variables, only maternal body mass curve reached significance as a factor predicting birth weight. This is in keeping with the findings of others. ${ }^{2}{ }^{3}$ It was apparent, however, that babies of mothers of Asian Indian origin were smaller than those of the other ethnic groups. Therefore, the babies' body mass curve was calculated in the same manner as for adults, from birth length and birth weight, and this measure was substituted for birth weight in the regression equation. In this model both maternal body mass curve and the area under the glucose curve emerged as significant factors in predicting body mass curve at birth $\left(r^{2}=10.5\right.$, $t=3.2$ and 3.1 respectively, $\mathrm{p}<0.01$ for both).

Birth length is notoriously difficult to measure. Nevertheless, we have attempted to derive a better index of fetal adiposity than simple birth weight and have found it to have a significant bearing on results of regression analysis, suggesting that maternal glycaemia does have an impact on fetal size independent of maternal weight.

Though macrosomia cannot be directly equated with morbidity, as long as maternal glycaemia during pregnancy can be shown to influence any aspect of fetal outcome the entity of gestational diabetes cannot be dismissed out of hand. We believe that screening programmes are still necessary to learn more about the condition. With the current interest in fetal nutrition and its influence on health in later life, now is not the time to be turning our backs on this important issue.

P S SHARP

R O'CONNOR

Northwick Park Hospital

Northwick

Middlesex HA1 3UJ

$S$ MCHARDY YOUNG J WOOTTON P FROST

Central Middlesex Hospital,

London NW10

1 Jarrett RJ. Gestational diabetes: a non-entity? $B M \mathcal{X}$ 1993;306: 37-8. (2 January.)

O'Sullivan JB, Gelliss SS, Tenney BO. Gestational blood glucose levels in normal and potentially diabetic women related to the birth weight of their infants. Diabetes 1966;15:466-70.

3 Green JR, Schumacher LB, Pawson IG, Partridge JC, Kretchmer $\mathrm{N}$. Influence of maternal body habitus and glucose tolerance on birth weight. Obstet Gynecol 1991;78:235-40.

EDITOR, - R J Jarrett documents the case against screening for diabetes in pregnancy. ${ }^{1}$ As studies have focused on the immediate pregnancy related complications of gestational diabetes it is not surprising that the value of such screening has not been properly investigated as far as long term complications are concerned. In the long term, the offspring may develop diabetes and the woman may suffer from progression of the disease to complications such as diabetic nephropathy and renal failure.

Evidence on the value of screening has been obtained mostly from countries with well developed health care systems. The prevailing conditions in other settings may be quite different: higher levels of perinatal morbidity and mortality as well as poor access to antenatal care and other health services. Therefore, it is inadvisable to extrapolate from those studies to disadvantaged populations. Furthermore, disadvantaged groups, both within our society ${ }^{2}$ and in developing countries, ${ }^{3}$ have been shown to be at high risk from gestational diabetes.

In the current economic climate it is not justi- 